\title{
Impact of Ict on Science Learning To Enhance Motivation of Secondary Level Students: An Analytical Study
}

\author{
Nandini Banerjee ${ }^{1}$, Amarnath Das ${ }^{2}$ \\ ${ }^{I}$ Research Scholar, Dept. Of Education, University of Kalyani, India \\ ${ }^{2}$ Research Scholar, Dept. Of Education, University of Kalyani, India
}

\begin{abstract}
Present century has witnessed a great progress in the field of science and technology which has led to extensive developments in the academic sector also. To cope with this growth in education sector, ICT i.e., Information and Communication Technology has a vital role to play. That is why the present study has emphasized to understand the impact of ICT on science learning to enhance motivation of secondary school students. From this angle of vision the objectives of this study have been stated and the gravity of the problem has been unfolded. On the basis of different researches a review has been made. The descriptive survey method followed by multivariate exploratory approach was employed for the present study. A purposive sampling technique was used. The sample has been consisted of 100 secondary school students of either sex of West Bengal government aided secondary schools. The sample is from eight secondary schools situated in different places of two districts viz. Burdwan and Bankura. A Likert type scale for Assessment of motivation in science learning with the impact of ICT was developed and standardised for the study. The data was organized and analyzed by factor analysis technique in SPSS Statistical Software. The extracted Principal component factors were interpreted. In course of this analysis and interpretation it was seen that the obtained first five principal component factors with highest loading clearly indicated the role of ICT in science learning motivation.
\end{abstract}

Keywords: ICT, Motivation, Principal Component Factor, Science Learning, Secondary Schools.

\section{Introduction}

The progress of any country depends largely on the quality of education. Education is considered as the foundation in each and every modern society. But now-a-days modern education is not restricted within the classroom. The recent development in science and technology has brought out the whole world outside the classroom. Information and Communication Technology (ICT) plays a crucial role in this respect. It is treated as the integral part for educational reforms and innovations at secondary and higher secondary level schools. In the education sector the national mission on education is emphasizing on the role of ICT is more to enhance the current enrollment rate in science stream of Higher Education by the end of the 12th Plan period. Through ICT provides enormous opportunity for all the teachers and experts to pool their collective wisdom for the benefit of every Indian learner. ICT means information and communication technologies and are described as a different set of technological tools and resources used to communicate, and to create, disseminate, store, and manage information. These technologies include computers, the Internet, e-mail, web based PC, Mobile phone, wireless sets, projectors, broadcasting technologies (radio and television) and different interactive boards. Thus ICT is a system that gathers different information or data to communicate over some distance with the help of modern technology. The integration of ICT into education has been assumed as the potential of the new technological system. ICT is not only the backbone of the Information Age, but also an important catalyst and tool for inducing educational reforms that change our students into productive knowledge workers.

In this regard a school has many important things to contribute for the development of a modern civilized society. The large contribution of a school to the development of a society is to nurture the science motivation in its students, so that they can cope with the pace of the progress. From this perspective, the ICT has an important role to play. In this study the investigator has tried to determine the impact of ICT on science learning motivation of the secondary level students. So, he has formulated some factors through this survey and its result. These factors have been considered as the necessary conditions to enhance science motivation. The main aim of this factorial study is to present these conditions. The investigator uses the knowledge base of ICT to examine relevant approaches to improve science motivation, although never loses sight of the fact that each situation is specific. He concedes that there seems to be more leeway for action the closer one gets to the school level, thus making planning for conditions difficult for those operating at the above-school level. Bearing this in mind, he suggests that a multi-level approach might be the most appropriate, particularly for developing countries. The importance of self-evaluation is emphasized, as is the fact that the evaluation process in itself can contribute to enhance science motivation. On the basis of this booklet, planners will certainly be better geared 
for dealing with the different factors involved in. It is expected that this piece of research work will be stepping stone for identifying the specific factors contributing to enhance science motivation.

\subsection{Objectives:}

- To construct a Likert type scale for assessment of motivation in science learning with the impact of ICT.

- To extract emerging principal component factors of science learning motivation with the effect of ICT.

- To interpret the extracted principal component factors of science learning motivation with the impact of ICT.

\subsection{Assumptions:}

- The impact of ICT in science learning motivation can be assessed.

- The impact of ICT in science learning motivation of students about an issue may vary.

- The impact of ICT in science learning motivation of students may normally vary.

\subsection{Delimitations:}

- Only secondary school students have been selected as sample.

- Kaiser principle in the matter of factor selection has been followed.

- Only orthogonal factor structure has been taken into consideration.

\subsection{Research Approach:}

\section{Methodology}

The present study is a descriptive survey followed by multivariate exploratory approach. The investigator has attempted to explore various principal component factors on the basis of field data.

\subsection{Sample:}

A purposive sampling technique has been employed. One hundred (100) secondary school students of West Bengal government aided secondary school constituted the sample. The sample is from eight secondary schools situated in different places of two districts viz. Burdwan and Bankura.

\subsection{Tool used:}

The investigator attempted to prepare a Likert type scale for Assessment of impact of ICT on Science Learning to enhance Motivation. For this the researcher has taken into account the following activities :

(1) the researcher studied the techniques of science motivation test preparation from relevant literature.

(2) he selected Likert type scale construction procedure as this type of scale is simple, easy to construct and may be as reliable as other types of motivation scales.

(3) he collected different ideas about ICT and its role to enhance motivation in science learning from various sources like available tools, books on psychological and educational tests, reports of earlier researches. Some educator's general opinion, and personal experiences of the investigator.

(4) Then he prepared an item pool.

(5) From the above item pool the researcher selected 20 opinions ideas so that it represents the whole item pool.

(6) The items were edited to suit their nature for the Likert type scale.

(7) The 20 selected items or statements were presented to experts including the supervisor of the project for judging appropriateness, pin-pointedness, language construction etc.

(8) From their reviews and opinions the investigator modified some statements.

(9) Finally the 20 statements were organised in a booklet each having 5 response alternatives and instructions were also written down and inserted in the front page of the test booklet.

(10) Thus the present test contains 20, all positive, statement each indicating one aspect of ICT's role to enhance motivation in science learning. The five response alternates are - strongly agree ; agree ; undecided; disagree; strongly disagree and scoring weights assigned are : strongly agree -4 ; agree -3 ; undecided -2 ; disagree -1 ; strongly disagree -0 .

(11) The present tool has adequate Face Validity as well as Construct Validity as the statements have been a sample of the item pool and expert's suggestions and criticisms have been taken into account in the construction of the present tool. Moreover factorial validity has also been established by the application principle components factor analysis. The above arguments ensure that the present has a high degree of validity as well as reliability. 


\subsection{Research Design:} the study.

According to the objectives of the present study the investigator used the under mentioned design for

- To prepare a Likert scale for assessment of impact of ICT on Science Learning to enhance Motivation.

- For the extraction of principal component factor, the collected data would be organized to put into the computer data sheet and finally with the application of SPSS package principle component analysis would be perform. After that Varimax rotation of the obtained factor structure would be perform again with the application of SPSS package for getting a meaningful factor structure.

- Finally the rotated factor structure would be interpreted logically taking into account tests (items).

\subsection{Design of the study: Showing in Figure-1}

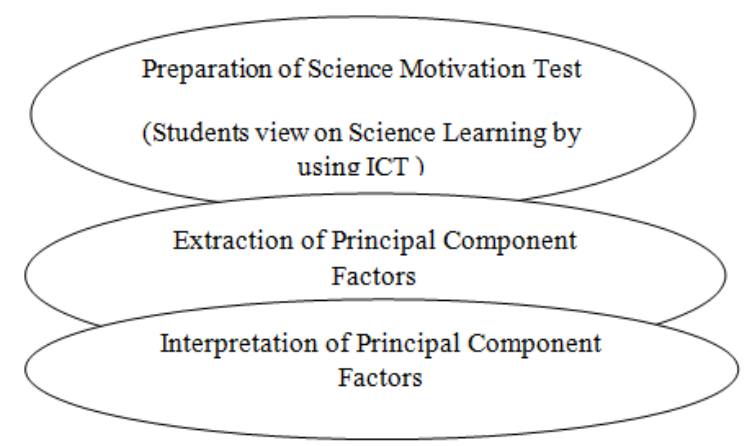

Fig. - 1

\subsection{Procedure of Data Collection:}

According to the objective of this study this investigator has formulated a tool which, in fact, Likert Type Scale and it helps to determine the views of secondary students in learning of science with ICT. He has applied this test to the 100 secondary school students. On the basis of student's response to each item the scoring has been made and thus total score has been determined. From this score list different statistical factors have been analysed and on the basis of such analysis, necessary factors have been determined. As a result of such measurement 5 factors have become possible to be determined.

\subsection{Computation Methods:}

Factor analysis based on carrying out a principal component analysis to find initial factors. The approach is adopted then the main part of the calculation is the finding of the eigenvalues and eigenvectors of the correlation matrix. Other methods of initial factor extraction are not so straight forward and are probably best done using one of the standard statistical packages. Varimax has much to recommend it as the standard method for factor rotation. It is quite easy to programme since it is done iteratively taking two factors at a time.

\subsection{Organisation of the Data:}

\section{Results: Extraction Of Principal Component Factors}

Prior to the input stage of data analysis the data must be organised for proper input into the computer system. Regardless of the type of computer or programme to be used, if data are poorly organised the researcher will have trouble to analyse their meaning. The data sheet of the study is organised in SPSS Statistical Software in computer. Then the data are coded and converted to the SPSS file. Variables are modified to numbers. These changes in coding are done by the computer as well as through a series of simple commands. After that the data is ready for analysis. 


\subsection{Presentation of Extracted Principal Component Factors (PCF) with Eigen Values:}

Table-1: Total Variance Explained

\begin{tabular}{|c|c|c|c|c|c|c|c|c|c|c|}
\hline \multirow{2}{*}{$\begin{array}{l}\text { Sl. } \\
\text { No. }\end{array}$} & \multirow{2}{*}{ Component } & \multicolumn{3}{|c|}{ Initial Eigen Values } & \multicolumn{3}{|c|}{$\begin{array}{c}\text { Extraction Sums of Squared } \\
\text { Loadings }\end{array}$} & \multicolumn{3}{|c|}{$\begin{array}{l}\text { Rotation Sums of } \\
\text { Squared Loadings }\end{array}$} \\
\hline & & Total & $\begin{array}{c}\% \text { of } \\
\text { Variance }\end{array}$ & $\begin{array}{c}\text { Cumulative } \\
\%\end{array}$ & Total & $\begin{array}{c}\text { \% of } \\
\text { Variance }\end{array}$ & $\begin{array}{c}\text { Cumulative } \\
\%\end{array}$ & Total & $\begin{array}{c}\text { \% of } \\
\text { Variance }\end{array}$ & $\begin{array}{c}\text { Cumulative } \\
\%\end{array}$ \\
\hline 1 & 12 & 6.143 & 30.717 & 30.717 & 6.143 & 30.717 & 30.717 & 4.155 & 20.773 & 20.773 \\
\hline 2 & 14 & 3.385 & 16.925 & 47.642 & 3.385 & 16.925 & 47.642 & 3.501 & 17.504 & 38.277 \\
\hline 3 & 16 & 2.098 & 10.489 & 58.131 & 2.098 & 10.489 & 58.131 & 3.374 & 16.868 & 55.145 \\
\hline 4 & 9 & 1.562 & 7.809 & 65.940 & 1.562 & 7.809 & 65.940 & 1.722 & 8.609 & 63.754 \\
\hline 5 & 15 & 1.196 & 5.981 & 71.921 & 1.196 & 5.981 & 71.921 & 1.633 & 8.167 & 71.921 \\
\hline 6 & 1 & .873 & 4.367 & 76.288 & & & & & & \\
\hline 7 & 6 & .801 & 4.003 & 80.291 & & & & & & \\
\hline 8 & 7 & .563 & 2.813 & 83.104 & & & & & & \\
\hline 9 & 8 & .541 & 2.703 & 85.807 & & & & & & \\
\hline 10 & 17 & .502 & 2.512 & 88.319 & & & & & & \\
\hline 11 & 11 & .466 & 2.332 & 90.651 & & & & & & \\
\hline 12 & 19 & .359 & 1.797 & 92.448 & & & & & & \\
\hline 13 & 20 & .326 & 1.628 & 94.076 & & & & & & \\
\hline 14 & 4 & .258 & 1.288 & 95.364 & & & & & & \\
\hline 15 & 2 & .229 & 1.146 & 96.509 & & & & & & \\
\hline 16 & 5 & .190 & .950 & 97.460 & & & & & & \\
\hline 17 & 3 & .172 & .862 & 98.321 & & & & & & \\
\hline 18 & 13 & .120 & .599 & 98.921 & & & & & & \\
\hline 19 & 18 & .111 & .555 & 99.476 & & & & & & \\
\hline 20 & 10 & .105 & .524 & 100.000 & & & & & & \\
\hline
\end{tabular}

Extraction Method: Principal Component Analysis.

Rotation Method: Varimax with Kaiser Normalization

\subsection{Scree Plot of Principal Component Factors Showing in Figure-2}

Scree Plot

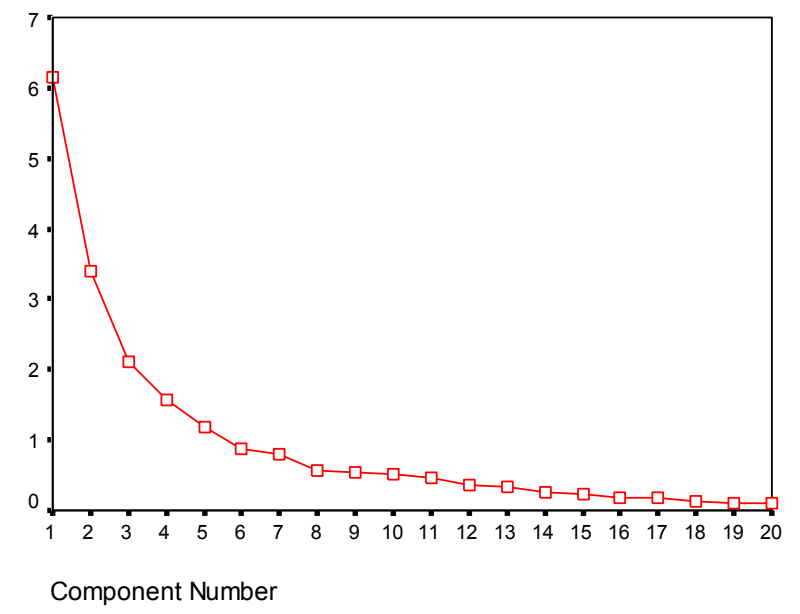

Fig. - 2

\subsection{Description and Interpretation of Principal Component Factors:}

Table - 2: List of Principal Component Factors

\begin{tabular}{|c|c|}
\hline Principal Component Factor (P. C. F.) & Name \\
\hline $\begin{array}{c}1^{\text {st }} \text { p. c. f. } \\
(\text { Eigen Value-6.143) }\end{array}$ & $\begin{array}{l}\text { Intrinsic Science Motivation in using ICT ( i.e. } 12^{\text {th }} \text { item: It is very interesting to know } \\
\text { about new science discoveries in Internet ) }\end{array}$ \\
\hline $\begin{array}{l}2^{\text {nd }} \text { p. c. f. } \\
\text { (Eigen Value-3.385) }\end{array}$ & $\begin{array}{l}\text { ICT enhance career prospects in science ( i.e. } 14^{\text {th }} \text { item: Realizing the process to solve } \\
\text { science problems in computer will help me in my career ) }\end{array}$ \\
\hline $\begin{array}{l}3^{\text {rd }} \text { p. c. f. } \\
\text { (Eigen Value- } 2.098)\end{array}$ & $\begin{array}{l}\text { ICT boost up Self-determination in science ( i.e. } 16^{\text {th }} \text { item: I spend a lot of time to prepare } \\
\text { my science project presentation in power-point) }\end{array}$ \\
\hline $\begin{array}{c}4^{\text {th }} \text { p. c. f. } \\
\text { (Eigen Value-1.562) }\end{array}$ & $\begin{array}{l}\text { ICT makes Self-efficacy in science ( i.e. } 9^{\text {th }} \text { item: I believe that the information obtained } \\
\text { from web sites will help me to get high score in science test ) }\end{array}$ \\
\hline $\begin{array}{c}5^{\text {th }} \text { p. c. f. } \\
\text { (Eigen Value-1.196) }\end{array}$ & $\begin{array}{l}\text { ICT provides active learning strategies to get best achievement in science ( i.e. } 15^{\text {th }} \text { item: It } \\
\text { is important to know the use of new strategies like Internet, E-mail etc., to get a high grade } \\
\text { in science ) }\end{array}$ \\
\hline
\end{tabular}


As the relevant data are presented in the above Table-2, it is observed that the $1^{\text {st }}$ principal component factor with the highest Eigen value of 6.143 has greater loading on the test, clearly indicate ICT improves students inherent motivation in science learning and it is a prime objective of student centric education. In man making process there should have maximum efforts on part of the teachers to identify the potential of pupils and fondly nurture it for attaining the success.

The $2^{\text {nd }}$ principal component factor has Eigen value of 3.385 demonstrate professional commitment of ICT to student's career prospect in science. Moreover ICT offers professional guidance for improvement of student science learning. It is appealing that stakeholders are expecting the skills to handle ICT as an insurance for secure vocation progression, not knowledge of knowledge sake. That is the economical view of ICT in science learning motivation.

The $3^{\text {rd }}$ principal component factor with Eigen value of 2.098 associated with the impact of ICT on student's self-determination improvement. The factor explains that ICT provides useful strategies to stimulate student's effort to do well in science learning. This is indeed, a sign of motivating and guiding student's willpower for the generation of great endeavor to learn science well.

The $4^{\text {th }}$ principal component factor with Eigen value of 1.562 demonstrated about the role of ICT in making Self-efficacy motivation in science learning. So that pupil could have mastery learning in science knowledge and skills. This factor is motivating learners to learn and achieve. It also makes them confident to perform better in science test.

The $5^{\text {th }}$ principal component factor with Eigen value of 1.196 mainly discussed about the student's motivation of scholastic attainment in science, i.e. Grade motivation. ICT offers proper educational guidance systematically to achieve the best grade in science. It stated about the learner's opportunity to score high in science test with the use of new strategies of ICT, like Internet, E-mail, digital library etc.

So, it is found from the data analysis and interpretation of the study that ICT has a great impact on science learning to enhance motivation. The obtained first five principal component factors with highest loading clearly indicate the role of ICT in science learning motivation.

\section{Conclusion}

The study reveals that the factors relating to motivation in science learning with the impact of ICT consisting of five principal component factors. That means enhancing the usage of ICT in the school level will enable enhancement of motivation in science learning. So, this study could serve as a base for education planers to deploy Technology based education in educational institutions.

\section{Suggestions For Further Study}

- In lieu of selecting secondary students as sample, students of other levels may be studied.

- In case of factor selection instead of Kaiser Principle other principles may be followed.

- For collecting information other techniques such as interview, observation may be used to create varieties in the method.

- Multiple techniques for data collection are to be employed in future. If possible some qualitative research methods like Phenomenology, Case-studies etc. may be used.

- Systematic factor analysis - both exploratory and confirmatory may be used.

\section{References}

[1]. Becker, H. J., 2000, Pedagogical Motivations for Student Computer Use that Leads to Student Engagement, Education Technology, Vol. 40, No. 5, pp. 5-17

[2]. Bhattacharya, I. \& Sharma, K., 2007, India in the knowledge economy - an electronic paradigm, International Journal of Educational Management, Vol. 21, No. 6, pp. 543- 568

[3]. Chandra, S. \& Patkar, V., 2007, ICTS: A catalyst for enriching the learning process and library services in India, The International Information \& Library Review, Vol. 39, No. 1, pp. 1-11

[4]. Collis, B., 1989, Using information technology to create new educational situations, International Congress on Education and Informatics, UNESCO, Paris

[5]. Glynn, S. M., Brickman, P., Armstrong, N., \& Taasoobshirazi, G., 2011, Science Motivation Questionnaire II: Validation With Science Majors and Nonscience Majors, Journal of Research in Science Teaching, Vol. 48, No. 10

[6]. Kennewell, S., Parkinson, J., \& Tanner, H., 2000, Developing the ICT capable school, Routledge Falmer, London

[7]. Mishra, R.C., 2005, Teaching of Information, APH Publishing Corporation, New Delhi, pp. 66-298

[8]. Pandey, V.C., 2001, Digital Technologies and Teaching Strategies, Isha Books Publisher, Delhi 